\title{
Prevalência de Dificuldades Sexuais em Parceiras de Homens Sexualmente Disfuncionais
}

Oswaldo Martins Rodrigues Júnior ${ }^{1}$

Vera Lúcia Andrade ${ }^{2}$

Moacir Costa $^{3}$

\section{RESUMO}

RODRIGUES Jr., O. M.; ANDRADE, V. L.; COSTA, M. Prevalência de dificuldades sexuais em parceiras de homens sexualmente disfuncionais. R. B. S. H.1(1): 1990.

O reconhecimento da prevalência de disfunções sexuais em mulheres parceiras de homens sexualmente disfuncionais deve conduzir-nos a melhor estratégia de tratamento para estes homens com disfunção de ereção, ejaculação prematura ou retardada, inibições de desejo sexual ou anorgasmia.

De um grupo de 32 mulheres, trazidas ao diagnóstico da disfunção sexual de seus parceiros sexuais, com a concordância destes, $88 \%$ referiam algum grau de disfunções sexuais, sendo que somente 9,38\% deviam esta disfunção à disfunção do parceiro.

Torna-se muito importante considerar a possível disfunção sexual da parceira sexual na estratégia de tratamento do paciente homem visando a meIhor adequação sexual posterior do casal.

1. Psicólogo; professor assistente de Psicologia Geral e Teorias e Técnicas Psicoterápicas II e supervisor do curso de Orientação Sexual de Adolescentes das Faculdades São Marcos; psicoterapeuta sexual do Instituto H. Ellis.

2. Psicóloga; estagiária do Instituto H. Ellis; psicoterapeuta corporal.

3. Psiquiatra com especialização em sexualidade humana; psicoterapeuta do Instituto H. Ellis.

Trabalho desenvolvido no Instituto H. Ellis, Centro Multidisciplinar para o Diagnóstico e Tratamento em Sexualidade. 


\section{SUMMARY}

RODRIGUES Jr., O. M.; ANDRADE, V. L.; COSTA, M. Prevalence of sexual dysfunctions among sexual partners of sexually dysfunctioning men. R. B. S. H.1(1): 1990.

The treatment for male sexual dysfunctions (erectile failure, premature or retarded ejaculation, inhibition of sexual desire or lack of orgasm) must consider the possibility of sexual dysfunctions in the female sexual partner.

In the diagnosis of male sexual dysfunctions 32 female sexual partners were interviewed when went along with the male patients. We found $88 \%$ of these women complaining of sexual dysfunctions, but only $9.38 \%$ had these dysfunctions due to the sexual dysfunctions of the male patients.

We will only have an actual sexual adequacy of the couple if we take into account the possibility of sexual dysfunctions in both, the male patients and their female sexual partners.

\section{INTRODUÇÃO}

O objetivo deste trabalho foi fazer um reconhecimento das disfunções sexuais, possivelmente existentes, nas parceiras sexuais de pacientes com queixas de disfunções sexuais que procuraram uma clínica privada, especializada no diagnóstico e no tratamento de disfunções sexuais. A existência de disfunções e dificuldades sexuais nas parceiras sexuais de homens sexualmente disfuncionais merece consideração na fase diagnóstica destes, visando o objetivo do diagnóstico, o tratamento a ser indicado, a solução mais adequada e satisfatória da disfunção sexual. O reconhecimento da possibilidade de disfunções sexuais entre as mulheres (esposas, noivas, namoradas, amantes) de homens com queixas de distúrbios sexuais torna-se importante para a conduta individualizada no tratamento deste paciente e, por extensão, do casal.

Consideramos disfunções sexuais femininas as seguintes dificuldades sexuais, segundo o conceito trifásico da resposta sexual humana de Kaplan (3):

- Inibição do desejo sexual. Desde a total inibição a uma diminuição da motivação para o ato sexual, seja por razões desenvolvimentais, seja por conflitos inconscientes ou sociais $(3,4)$. A inibição do desejo sexual, a disfunção sexual geral e o vaginismo são classificadas em primária e secundária, sendo primária quando o distúrbio ocorre desde o início da vida sexual, e secundária quando o distúrbio surge após um período de normalidade sexual. 
- Disfun ção sexual geral. Dificuldades relacionadas à fase de excitação: lubrificação vaginal insuficiente e/ou falta de satisfação com o contato sexual, acompanhadas ou não de dispareunia $(2,4)$.

- Disfunção orgásmica. Dificuldade ou incapacidade de obter orgasmos, seja de maneira absoluta ou situacional, seja primária ou secundária (2). Quando absoluta, o orgasmo nunca foi obtido anteriormente de nenhuma forma, em nenhuma circunstância, enquanto que com a disfunção orgásmica situacional existe a falta de orgasmos circunstancialmente. Na disfunção orgásmica primária, o orgasmo é conseguido pela masturbação sem que isto ocorra no relacionamento sexual.

- Vaginismo. É um espasmo involuntário dos músculos circundantes da entrada vaginal quando ocorre uma tentativa de introdução vaginal, conduzindo à impossibilidade de uma relação sexual intravaginal e o surgimento de muitas dores com a tentativa (2).

- Outras dificuldades relacionadas à não adequação sexual entre os parceiros sexuais (4).

\section{MATERIAIS E MÉTODOS}

Os dados foram obtidos através da análise retrospectiva da entrevista psicológica a que foram submetidas mulheres devido às disfunções sexuais de seus parceiros. A convocação das parceiras sexuais para uma entrevista psicológica estruturada dependeu da história e da evolução da disfunção sexual do paciente a da aceitação, pelo paciente homem, da participação de sua parceira sexual no processo diagnóstico e futuro tratamento de sua disfunção sexual. A convocação foi feita através do paciente que deveria discutir com a parceira sua vinda para a entrevista.

De um grupo de 525 pacientes homens queixando-se de disfunções sexuais (disfunção erétil, ejaculação prematura, ejaculação retardada, inibição de desejo, anorgasmia), foram convocadas, devido à aceitação desta participação pelos pacientes, as parceiras sexuais fixas de 58 pacientes $(11,05 \%)$ e destas, 32 compareceram para a entrevista psicológica $(55,17 \%)$. A idade média foi de 38 anos e 2 meses, variando de 25 a 60 anos. Uma vez que a condição de parceira sexual não corresponde ao estado civil, a distribuição deste encontra-se na Tabela 1. A Tabela 2 mostra a distribuição do grau de escolaridade, onde a maioria tem grau universitário completo, apesar de não exercer profissões fora de casa (Tabela 3). 
Tabela 1 - Estado civil das mulheres estudadas.

\begin{tabular}{lr}
\hline Casada com o paciente & $25(78,13 \%)$ \\
Solteira & $3(9,38 \%)$ \\
Separada, com outra relação & $2(6,25 \%)$ \\
Separada & $1(3,13 \%)$ \\
Vivendo junto & $1(3,13 \%)$ \\
\hline
\end{tabular}

Tabela 2 - Grau de escolaridade das mulheres estudadas.

\begin{tabular}{lr}
\hline Primeiro grau completo & $2(6,25 \%)$ \\
Primeiro grau incompleto & $2(6,25 \%)$ \\
Segundo grau completo & $5(15,62 \%)$ \\
Segundo grau incompleto & $5(15,62 \%)$ \\
Terceiro grau completo & $10(31,25 \%)$ \\
Terceiro grau incompleto & $1(3,13 \%)$ \\
Analfabeta & $1(3,13 \%)$ \\
Sem informações & $6(18,75 \%)$ \\
\hline
\end{tabular}

Tabela 3 - Distribuição de profissões entre as mulheres estudadas.

\begin{tabular}{lr}
\hline Do lar & $16(50,00 \%)$ \\
Professora & $4(12,50 \%)$ \\
Advogada & $2(6,25 \%)$ \\
Doméstica & $2(6,25 \%)$ \\
Decoradora & $1(3,13 \%)$ \\
Empresária & $1(3,13 \%)$ \\
Estudante & $1(3,13 \%)$ \\
Lojista & $1(3,13 \%)$ \\
Recepcionista & $1(3,13 \%)$ \\
Secretária & $1(3,13 \%)$ \\
Veterinária & $1(3,13 \%)$ \\
Vendedora & $1(3,13 \%)$ \\
\hline
\end{tabular}

\section{RESULTADOS}

Os sentimentos com relação ao corpo demonstraram ser positivos em 16 mulheres (50\%), com referências de adequação e aceitação do corpo. Os sentimentos negativos foram referidos por 7 mulheres $(, 21,87 \%)$, que demonstravam não aceitar o corpo e sentirem no ina- 
dequado. As 9 mulheres restantes $(28,12 \%)$ não demonstraram claramente a aceitação ou não do corpo.

O desenvolvimento psico-sexual adequado associa-se a uma vida sexual adulta saudável. Foi considerado adequado um desenvolvimento psico-sexual composto por um ambiente familiar receptivo, com a existência de experiências sexuais gratificantes e bem integradas emocionalmente, tais como jogos e brincadeiras de cunho sexual, a exemplo dos enunciados por Costa (1).

Encontramos nesta amostra 7 mulheres $(21,87 \%)$ das quais depreendemos um desenvolvimento psico-sexual adequado contra 24 mulheres (75,00\%) com inadequação do desenvolvimento da psicosexualidade. De uma mulher não tínhamos informações suficientes ao nível diagnóstico para melhor compreensão desenvolvimental.

Quanto à menarca, 19 destas mulheres (59,37\%) tiveram conhecimento antecipado sobre a menstruação através de parentes ou amigas; 8 (25\%) não obtiveram nenhuma informação na época; não obtivemos informações sobre o assunto em 5 casos (15,12\%). Com relação aos sentimentos quanto à menarca, 14 mulheres $(43,75 \%)$ referiram sentimentos positivos, enquanto 12 mulheres referiram sentimentos negativos; não foram obtidas informações em 6 (18,75\%) casos. A idade média destas mulheres para a menarca é de 12 anos e 6 meses, variando de 11 a 15 anos.

A idade para a iniciação sexual alcançou a média de 20 anos e 6 meses, variando de 12 a 30 anos. As pessoas com quem estas mulheres tiveram sua iniciação sexual encontram-se distribuídas a apresentadas na Tabela 4. A idade média das mulheres que referiram ter tido a primeira relação sexual com o marido, após o casamento, foi de 42 anos e 4 meses, variando de 26 a 60 anos. As mulheres que tiveram sua primeira relação sexual com o namorado (incluindo se este for seu atual marido) apresentaram a idade média de 32 anos e 8 meses, variando de 25 a 40 anos. A maioria destas mulheres (62,5\%) referiu sentimentos negativos relativos à iniciação sexual. Tabela 4 - Parceiro para iniciação sexual das parceiras de homens sexual-
mente disfuncionais.

\begin{tabular}{lr}
\hline Marido ap6s casar & $16(50,00 \%)$ \\
Namorado & $7(21,87 \%)$ \\
Atual marido & $5(15,62 \%)$ \\
Noivo & $2(6,25 \%)$ \\
Parceiro eventual & $1(3,13 \%)$ \\
Sem informações & $1(3,13 \%)$ \\
\hline
\end{tabular}


O sentimento de disponibilidade para a atividade sexual destas mulheres encontra-se referida na Tabela 5, enquanto que a freqüência da atividade sexual encontra-se na Tabela 6.

Tabela 5 - Disponibilidade para a atividade sexual das parceiras de homens com disfunções sexuais.

\begin{tabular}{lr} 
Positiva & $16(50,00 \%)$ \\
Diminuída & $7(21,87 \%)$ \\
Negativa & $5(15,62 \%)$ \\
Indiferente & $1(3,13 \%)$ \\
Sem informações & $3(9,38 \%)$ \\
\hline
\end{tabular}

Tabela 6 - Freqüência da atividade sexual referida por parceiras de homens com disfunções sexuais.

\begin{tabular}{ll}
\hline 1 vez por semana & $4(12,50 \%)$ \\
2 vezes por semana & $3(9,38 \%)$ \\
3 vezes por semana & $1(3,13 \%)$ \\
4 vezes por semana & $2(6,25 \%)$ \\
Diária & $1(3,13 \%)$ \\
3 vezes ao mês & $2(6,25 \%)$ \\
Nula & $8(25,00 \%)$ \\
Diminuída & $2(6,25 \%)$ \\
Sem informaçóes & $9(28,12 \%)$ \\
\hline
\end{tabular}

A idade de início da masturbação ocorreu em média de 15 anos e 2 meses, variando de 5 a 34 anos, sendo que 7 desta amostra $(21,87 \%)$ nunca se masturbaram. Os sentimentos positivos quanto à prática da masturbação são referidos por $64,71 \%$.

Quanto às fases da resposta sexual humana (Kaplan, 3) encontramos preservada a fase de desejo em $53,12 \%$, em $34,37 \%$ percebeu-se diminuição do desejo sexual, e em 12,5\% encontramos ausência do desejo sexual.

A fase de excitação sexual mostrou-se preservada em $80 \%$ da amostra, sendo que apenas 1 mulher tinha ausência total de lubrificação vaginal e outros sinais de excitação sexual, enquanto nas restantes $(16,67 \%)$ havia sinais de dificuldades relacionadas a esta fase da resposta sexual humana.

A fase de orgasmo mostrou-se preservada em 19 mulheres (59,38\%), e a ausência de orgasmo foi referida por $21,9 \%$, enquanto 
as demais referiam dificuldade na obtenção do orgasmo durante a atividade sexual com penetração vaginal.

O quadro de disfunção sexual geral primária apresentou-se apenas em 1 mulher (3,13\%).

A inibição do desejo sexual atinge 40,63\% das mulheres estudadas e as várias formas encontram-se distribuídas na Tabela 7.

Tabela 7 - Prevalência dos tipos de inibição do desejo sexual (IDS) entre as parceiras de homens com disfunçōes sexuais.

\section{Tipo de IDS}

- Primária

$6(46,15 \%)$

- Secundária

$3(23,08 \%)$

- Secundária à disfunção sexual do parceiro

$2(15,38 \%)$

- Secundária à depressão

$1(7,69 \%)$

- Situacional à disfunção sexual do parceiro

$1(7,69 \%)$

O quadro das formas de disfunções de orgasmo, que atinge 25\% desta amostra, encontra-se delineado na Tabela 8.

Tabela 8 - Prevalência dos tipos de anorgasmia entre as parceiras de homens com disfunções sexuais.

\section{Tipo de Anorgasmia}

- Situacional

$4(50,00 \%)$

- Absoluta

$2(25,00 \%)$

- Secundária

$1(12,50 \%)$

- Secundária à disfunção sexual do parceiro

$1(12,50 \%)$

A inadequação sexual, enquanto desajuste sexual relacionado ao casal, foi detectada em 1 das mulheres da amostra (3,13\%).

\section{CONCLUSÕES}

Quanto à vinda parcial das parceiras convocadas (55,17\%), podemos deduzir três hipóteses possíveis:

1. Os pacientes não lhes passaram a convocação; elas não souberam que seria necessária ou útil sua participação no diagnóstico das disfunções sexuais de seus parceiros.

2. Receberam a convocação verbal através do paciente, mas se recusaram a vir (justificativa dada pelo paciente). 
3. Receberam a convocação verbalmente e não a consideraram ou o casal não considerou necessária a presença da parceira sexual no diagnóstico proposto.

O estado civil destas mulheres leva-nos a concluir que os pacientes com disfunções sexuais, e que têm a participação das parceiras no processo de diagnóstico e tratamento para aquelas disfunções, não procuram fora do casamento outros relacionamentos sexuais fixos ou ocasionais, talvez pela dificuldade sexual que os torna inseguros.

Apesar de serem um grupo de mulheres com escolaridade acima da média (31,25\% com grau universitário), elas não se mostram economicamente emancipadas e mantêm os mesmos papéis previamente estabelecidos socialmente para as mulheres: 50\% trabalham em casa, além de $21,88 \%$ em trabalhos considerados próprios de mulheres, com baixo status social (recepcionista, secretária, vendedora, doméstica).

Observando a idade na primeira relação sexual e o parceiro para esta, podemos perceber que há duas gerações que se mostram comportamentalmente diferenciadas: as mulheres que referiram a primeira relação sexual após o casamento são 9 anos e 8 meses, em média, mais velhas do que aquelas que tiveram a primeira relação sexual com o namorado (mesmo que sendo o atual marido). A virgindade parece ter sido mais valorizada pela geração que se casou no final da década de cinqüenta, quando estas mulheres só tiveram sua primeira relação sexual após o casamento.

A freqüência da atividade sexual nula mostra-se coerente com a disfunção sexual do parceiro em $25 \%$ das mulheres estudadas.

As disfunções de desejo nestas mulheres são essencialmente primárias, independendo da disfunção sexual de seus parceiros, sendo que apenas 3 mulheres desenvolveram a inibição do desejo sexual após a disfunção do parceiro $(23,07 \% 0)$.

Encontramos apenas 1 mulher com anorgasmia secundária à disfunção sexual do parceiro, aparentemente significando que tais disfunções, quando existem num casal, são anteriores ao aparecimento de disfunções sexuais dos parceiros sexuais.

As disfunções sexuais presentes nesta amostragem (88\%) não se mostram resultantes das disfunções sexuais dos pacientes que estavam procurando solução para suas disfunções, o que ocorreu em apenas 3 mulheres (9,38\%). Estes resultados apontam para a conclusão de que as disfunções sexuais masculinas não são causas comuns de disfunções sexuais entre as parceiras dos homens que as têm, ou não estão correlacionadas com elas.

A solução do problema sexual do paciente poderá não 
resolver a inadequação sexual do casal, e menos ainda as dificuldades sexuais de suas parceiras, fato também apontado por Kaplan (2). As disfunções destas mulheres somente seriam resolvidas se fossem resultado direto das disfunções destes homens.

As disfunções sexuais femininas decorrem especialmente de relacionamentos conjugais frustradores, não guardando obrigatoriamente relação com as disfunções sexuais de seus companheiros.

Para haver a adequação sexual do casal, necessitamos considerar as possíveis disfunções sexuais existentes nas mulheres de homens que procuram solucionar suas disfunções sexuais, sejam estas de origem psicológica ou mesmo orgânica. Torna-se importante, além de darmos atenção às disfunções sexuais isoladamente, nos preocuparmos com a adequação sexual do casal que nos procura com dificuldades sexuais.

\section{REFERÊNCIAS BIBLIOGRÁFICAS}

1. COSTA, M. Sexualidade na Adolescência, Dilemas e Crescimento. Porto Alegre, L \& PM Editores, 5⿳亠丷a edição, 1987.

2. KAPLAN, H. S. A Nova Terapia do Sexo. Rio de Janeiro, Editora Nova Fronteira, 5ạ edição, 1977.

3. . O Desejo Sexual. Rio de Janeiro, Editora Nova Fronteira, 1983.

4. MALDONADO, M. T. Psicologia da atração sexual. In: Cavalcanti, R. C. \& Vitiello, N. Sexologia I - Textos do I Encontro Nacional de Sexologia. Rio de Janeiro, Femina Livro, 1984. 